\title{
Seismogenic zone structure of the southern Middle America Trench, Costa Rica
}

\author{
H. R. DeShon, ${ }^{1}$ S. Y. Schwartz, ${ }^{1}$ S. L. Bilek, ${ }^{2}$ L. M. Dorman, ${ }^{3}$ V. Gonzalez, ${ }^{4}$ \\ J. M. Protti, ${ }^{4}$ E. R. Flueh, ${ }^{5}$ and T. H. Dixon ${ }^{6}$ \\ Received 5 November 2002; revised 22 May 2003; accepted 1 July 2003; published 21 October 2003.
}

[1] The shallow seismogenic portion of subduction zones generates damaging large and great earthquakes. This study provides structural constraints on the seismogenic zone of the Middle America Trench offshore central Costa Rica and insights into the physical and mechanical characteristics controlling seismogenesis. We have located 300 events that occurred following the $M_{W}$ 6.9, 20 August 1999, Quepos, Costa Rica, underthrusting earthquake using a three-dimensional velocity model and arrival time data recorded by a temporary local network of land and ocean bottom seismometers. We use aftershock locations to define the geometry and characteristics of the seismogenic zone in this region. These events define a plane dipping at $19^{\circ}$ that marks the interface between the Cocos Plate and the Panama Block. The majority of aftershocks occur below $10 \mathrm{~km}$ and above $30 \mathrm{~km}$ depth below sea level, corresponding to $30-35 \mathrm{~km}$ and $95 \mathrm{~km}$ from the trench axis, respectively. Relative event relocation produces a seismicity pattern similar to that obtained using absolute locations, increasing confidence in the geometry of the seismogenic zone. The aftershock locations spatially correlate with the downdip extension of the oceanic Quepos Plateau and reflect the structure of the main shock rupture asperity. This strengthens an earlier argument that the 1999 Quepos earthquake ruptured specific bathymetric highs on the downgoing plate. We believe that subduction of this highly disrupted seafloor has established a set of conditions which presently limit the seismogenic zone to be between 10 and $35 \mathrm{~km}$ below sea level. INDEX TERMS: 7209 Seismology: Earthquake dynamics and mechanics; 7220 Seismology: Oceanic crust; 7230 Seismology: Seismicity and seismotectonics; 8123 Tectonophysics: Dynamics, seismotectonics; 8150 Tectonophysics: Plate boundary — general (3040); KEYWORDS: seismogenic zone, Costa Rica, Quepos aftershocks, subduction zone, earthquake location

Citation: DeShon, H. R., S. Y. Schwartz, S. L. Bilek, L. M. Dorman, V. Gonzalez, J. M. Protti, E. R. Flueh, and T. H. Dixon, Seismogenic zone structure of the southern Middle America Trench, Costa Rica, J. Geophys. Res., 108(B10), 2491, doi:10.1029/2002JB002294, 2003.

\section{Introduction}

[2] Most large or great $\left(M_{W}>7\right)$ underthrusting earthquakes at subduction zones nucleate within a shallow region of unstable slip on or near the converging plate interface, termed the seismogenic zone. These earthquakes generate at least $80 \%$ of the total world-wide seismic moment release

\footnotetext{
${ }^{1}$ Department of Earth Sciences and the Institute of Geophysical and Planetary Physics, University of California, Santa Cruz, Santa Cruz, California, USA.

${ }^{2}$ Department of Geological Sciences, University of Michigan, Ann Arbor, Michigan, USA.

${ }^{3}$ Scripps Institution of Oceanography, University of California, San Diego, La Jolla, California, USA.

${ }^{4}$ Observatorio Vulcanológico y Sismológico de Costa Rica, Universidad Nacional, Heredia, Costa Rica.

${ }^{5}$ Forschungszentrum für Marine Geowisssenschaften (GEOMAR), Christian-Albrechts-University of Kiel, Kiel, Germany.

${ }^{6}$ Rosenstiel School of Marine and Atmospheric Science, University of Miami, Miami, Florida, USA.
}

Copyright 2003 by the American Geophysical Union. 0148-0227/03/2002JB002294\$09.00 [e.g., Pacheco and Sykes, 1992] and pose significant seismic hazard, especially to low-lying coastal areas. Globally, updip and downdip limits of seismogenic zones vary significantly, suggesting that a complex interaction of processes controls the generation of shallow underthrusting seismicity. The updip limit, marked by the transition from stable or aseismic slip to stick-slip behavior, may occur between the trench axis and $15 \mathrm{~km}$ depth below sea level, while the downdip transition to stable sliding occurs between $10 \mathrm{~km}$ and $>40 \mathrm{~km}$ depth [Zhang and Schwartz, 1992; Pacheco et al., 1993; Tichelaar and Ruff, 1993]. These seismogenic limits at subduction margins have primarily been identified through poorly constrained offshore seismicity recorded locally by land-based stations or through regional and teleseismic earthquake location studies. Such studies provide few constraints for differentiating between the thermal, mechanical, hydrological, and compositional interactions potentially responsible for controlling shallow subduction zone seismicity.

[3] Local-scale earthquake location studies of small magnitude earthquakes lend insight into seismogenic zone 
processes by providing high-resolution images of individual seismogenic zones [e.g., Nishizawa et al., 1990; Hino et al., 1996; Husen et al., 1999; Shinohara et al., 1999]. Local seismic studies are well-suited to define the geometry and volume of seismogenic zones and to constrain the thickness of the zone along strike and downdip. Such constraints can in turn be compared to or used in conjunction with other geophysical data to better understand seismogenic zone processes.

[4] This study investigates seismogenic zone structure along the southern segment of the Middle America Trench offshore Costa Rica. The Costa Rica-Nicaragua margin is a focus site of the NSF MARGINS and international Seismogenic Zone Experiment (SEIZE). This margin exhibits significant along-strike variability in seafloor morphology, plate geometry, and temporal characteristics of seismicity across a short $(<400 \mathrm{~km})$ segment of trench. Two peninsulas, the Osa and Nicoya, overlie the seismogenic zone offshore Costa Rica, making the margin particularly wellsuited for land and ocean geophysical studies. Multiple reflection, refraction, and wide-angle seismic profiles [Hinz et al., 1996; Stavenhagen et al., 1998; Ye et al., 1996; Christeson et al., 1999; Sallarès et al., 1999, 2001; McIntosh et al., 2000; Walther, 2003], a three-dimensional (3-D) seismic study [Shipley et al., 1992], high-resolution bathymetry [Ranero and von Huene, 2000; von Huene et al., 2000], and land GPS data [Dixon, 1993; Lundgren et al., 1999] exist for the area, providing fundamental structural models and geophysical information. Earthquake locations within the Costa Rica-Nicaragua seismogenic zone are, however, poorly constrained, especially in depth, by local onshore short-period networks, with seismicity forming a cloud-like pattern around the shallow plate interface [Protti et al., 1994]. In an effort to increase the quality and quantity of seismic and geodetic data in the region and provide improved understanding of the seismic process, the University of California-Santa Cruz, the Observatorio Vulcanológico y Sismológico de Costa Rica (OVSICORI-UNA), Scripps Institution of Oceanography (SIO), the University of Miami, and Forschungszentrum für Marine Geowisssenschaften (GEOMAR) have undertaken a series of seismic and geodetic experiments in Costa Rica, which we term CRSEIZE. The seismic portion of this experiment included deployment of land and ocean bottom (OBS) seismic arrays across central Costa Rica and the Osa Peninsula and across the northern Nicoya Peninsula between September 1999 and June 2001 (Figure 1) (hereafter the Osa and Nicoya experiments). The OBS were deployed and recovered during GEOMAR R/V Sonne cruise S0 144/1a and /3b and SIO $\mathrm{R} / \mathrm{V}$ Melville cruise NEM004.

[5] On 20 August 1999, a $M_{W} 6.9$ underthrusting earthquake occurred offshore the city of Quepos in central Costa Rica (Figure 1). The event was preceded by a $M_{W} 5.5$ foreshock on 10 August 1999 and generated much aftershock activity. The magnitude of the main shock is consistent with the largest magnitudes $\left(M_{W} 7.0\right)$ recorded along the central Costa Rica margin [Protti et al., 1994, 1995a], and hence, the aftershock sequence was assumed to have ruptured much of the interplate seismogenic zone. The Quepos earthquake occurred 19 days prior to scheduled station deployment for the Osa experiment, originally designed to be placed on and offshore the Osa Peninsula.

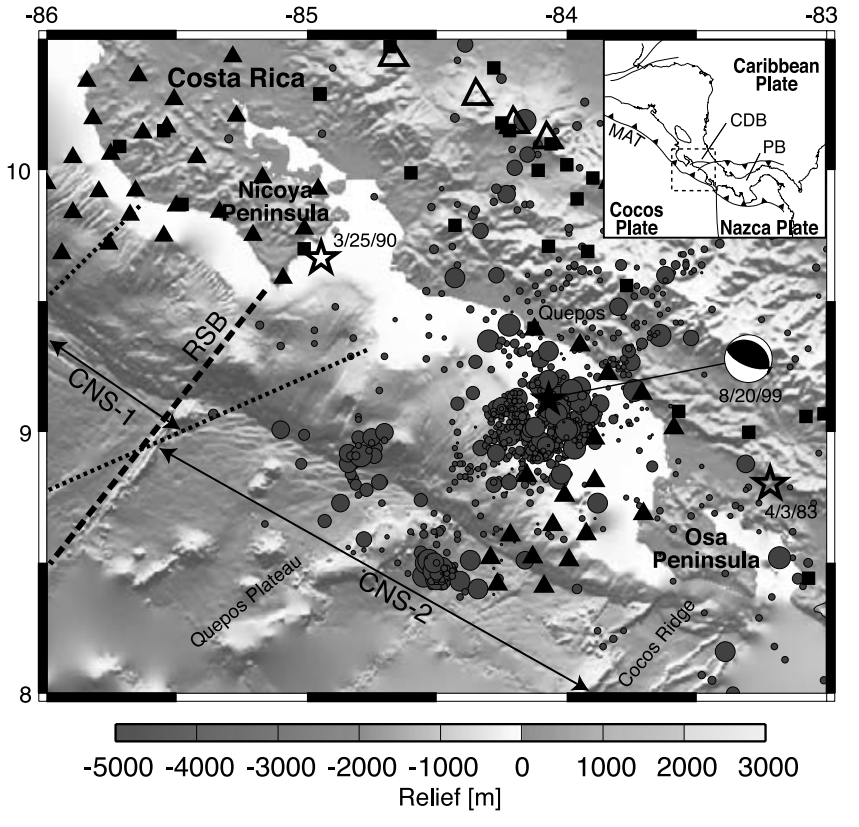

Figure 1. Overview map of Costa Rica tectonics and CRSEIZE experiments. Cocos plate oceanic crust formed at the Cocos-Nazca Spreading Center from 22.7 to $19.4 \mathrm{Ma}$ and from 19.5 to $14.5 \mathrm{Ma}$ (CNS-1 and CNS-2 from Meschede et al. [1998] and Barckhausen et al. [2001]) subducts along the Middle America Trench (MAT) offshore central and southern Costa Rica. The transition in the upper plate from Caribbean Plate to Panama Block (PB) occurs across the diffuse faulting of the central Costa Rica deformed belt (CDB) [Marshall et al., 2000]. Smooth seafloor offshore the Nicoya Peninsula abruptly transitions to seamount-dominated seafloor at the rough/smooth boundary (RSB). Thickened crust of the Cocos Ridge subducts beneath and uplifts the Osa Peninsula. The Osa Experiment recorded the aftershock sequence of the 1999 Quepos underthrusting earthquake; shown is the local OVSICORI location (black star) paired with the Harvard Centroid moment tensor solution. Initial database locations of aftershocks through the 1-D IASP91 model are scaled by local magnitude (maximum $M_{L}=4.3$ ). Open triangles, major volcanoes; black triangles, CRSEIZE seismometer locations; black squares, OVSICORI network; open stars, recent $M_{w} \geq 7.0$ underthrusting earthquakes. Bathymetry is from von Huene et al. [2000].

The land and ocean bottom seismic stations were hence relocated to better record the aftershock sequence of the Quepos earthquake. In this paper we present aftershock locations of the Quepos underthrusting earthquake and use them to define the geometry of the seismogenic plate interface northwest of the Osa Peninsula. The goals of this study include (1) determining the best $1-\mathrm{D}$ and $3-\mathrm{D}$ velocity models for the southern Costa Rica margin; (2) locating small magnitude $\left(1.0 \leq M_{L} \leq 4.0\right)$ earthquakes within these velocity models; (3) exploring the trade-off between absolute and relative earthquake locations in a three dimensional velocity environment; (4) determining the updip and downdip extent and geometry of recorded seismogenic zone earthquakes offshore central Costa Rica; (5) recognizing 
patterns in the seismicity defining the subducting plate interface; and (6) correlating seismicity with existing thermal and mechanical models for seismogenic zones.

\section{Tectonic Setting and Seismicity of Costa Rica}

[6] The western Costa Rican margin varies morphologically, compositionally, and seismically along strike, offering an unique opportunity to correlate variable subduction characteristics with seismicity patterns. Along the Pacific coast of Costa Rica, oceanic Cocos plate subducts at the Middle America Trench (MAT) at $\sim 9 \mathrm{~cm} / \mathrm{yr}$ [DeMets, 2001] (Figure 1). The resultant volcanic arc extends from central Costa Rica through Mexico and is bounded to the south by faults associated with the Central Costa Rica deformed belt (CCRDB) [Marshall et al., 2000]. The CCRDB marks the diffuse boundary between stable Caribbean plate in northern Costa Rica and the deforming Panama Block microplate in southern Costa Rica (Figure 1) [Marshall et al., 2000]. The morphology, age, and formation history of the Cocos Plate also varies along strike of the MAT [von Huene et al., 1995; Meschede et al., 1998; Ranero and von Huene, 2000; von Huene et al., 2000; Barckhausen et al., 2001]. The incoming plate exhibits low but variable thermal gradients [Langseth and Silver, 1996; Fisher et al., 2001] and is overlain by a small, but variable $(<500 \mathrm{~m}$ to $>1 \mathrm{~km})$, sediment layer [Shipley et al., 1992; Walther, 2003].

[7] von Huene et al. [1995] divided the western Costa Rican margin into three morphologic and bathymetric sections: the southern (Osa) segment, the central (seamount) segment, and the northern (Nicoya) segment. In the Osa segment, the Cocos Ridge, a region of $11-12 \mathrm{~km}$ thick, young oceanic crust $(\sim 15 \mathrm{Ma})$ that traces the interactions of the Galapagos hot spot on the Cocos plate [Hey, 1977], subducts causing relatively high uplift rates on the Osa Peninsula [Gardner et al., 1992; von Huene et al., 1995; Fisher et al., 1998] and back arc compressional deformation [Dixon, 1993]. Along central Costa Rica, seamounts cover $\sim 40 \%$ of the seafloor and range in size from 1 to $2.5 \mathrm{~km}$ high and 10 to $20 \mathrm{~km}$ wide [von Huene et al., 1995, 2000] (Figure 1). As these features subduct, they erode and deform the forearc wedge, uplift the forearc from below, and possibly erode the overlying continental plate [Ranero and von Huene, 2000]. North of the seamount domain, smoother, older oceanic crust $(\sim 19-24 \mathrm{Ma})$ derived from both the East Pacific Rise and the Cocos-Nazca Spreading Center subducts under the Nicoya Peninsula.

[8] The seismicity patterns of Costa Rica reflect the interactions of Caribbean Plate, Panama Block, and Cocos Plate. Protti et al. [1994, 1995a] divided the western Costa Rica margin into northern (Nicoya), central, and southern (Osa) components based on the changing nature of the Wadati-Benioff zone along strike of the MAT. Along the Osa segment, Protti et al. [1994, 1995a] traced the slab no deeper than $50 \mathrm{~km}$. The absence of deep slab structure reflects subduction of the buoyant Cocos Ridge. The most recent large event in the Osa segment, the 1983 Gulfo Dulce $M_{w} 7.4$ underthrusting earthquake (Figure 1), exhibited a complex rupture history indicative of increased coupling due to ridge subduction [Adamek et al., 1987; Tajima and Kikuchi, 1995]. Events of $M_{s} 7.6$ occur along the Osa segment with an average recurrence interval of 40 years. The central segment, historically the most seismically active region on the margin, can generate earthquakes up to $M_{s} 7.0$ over a short recurrence interval [Protti et al., 1995b]. Within this segment Protti et al. [1994, 1995a] found a shallow slab dip of $\sim 20^{\circ}$, steepening to $60^{\circ}$ at depth, and a steepening of the slab from south to north. The $1990 M_{w} 7.0$ Nicoya Gulf earthquake occurred within this segment south of the Nicoya Peninsula along the downdip extension of the subducting Fisher Seamount Chain (Figure 1) and has been proposed to have ruptured a seamount at depth [Protti et al., 1995b; Husen et al., 2002]. The northern Nicoya Peninsula segment is recognized as a current seismic gap [Nishenko, 1991], with the potential for large $M_{s} 7.7$ earthquakes and a recurrence interval of 50 years.

[9] The 1999 Quepos underthrusting earthquake occurred at the southern edge of the morphologically defined seamount-dominated segment of the Costa Rica margin. Best estimates of its depth using the OVSICORI epicenter place the event at $21 \pm 4 \mathrm{~km}$ [Bilek et al., 2003], near the plate interface as defined by available refraction information and consistent with the Harvard CMT thrust focal mechanism. The event occurred along the downdip extension of the incoming Quepos Plateau, a highly disrupted string of seamounts and bathymetrically high crust (Figure 1). The moment release history consisted of two main subevents with a total rupture length equal to the width of the Quepos Plateau [Bilek et al., 2003]. Bilek et al. [2003] proposed that the Quepos event represented rupture of specific topographic highs within the Quepos Plateau chain acting as asperities and that the size of these asperities limited the main shock rupture extent.

\section{Method}

\subsection{Experiment Setup and Data Processing}

[10] The Osa seismic array covered $\sim 1600 \mathrm{~km}^{2}$ and extended from the central Costa Rica coast and northwest Osa Peninsula to seaward of the Middle America Trench (Figures 1 and 2). The land array consisted of one broadband Streckeisen STS-2 and five short-period L-22 threecomponent seismometers, and the ocean bottom array consisted of 12 four-channel (three-component broadband plus hydrophone) ocean bottom seismometers (OBS) operated at SIO. Land data were collected in continuous $40 \mathrm{~Hz}$ mode and processed using PASSCAL software (version 1.9.20). OBS data were collected in $64 \mathrm{~Hz}$ or $128 \mathrm{~Hz}$ mode and processed at SIO. OBS data processing included correcting timing, calculating orientation on the seafloor from magnetic locking compasses [Sauter and Dorman, 1995], and calculating response information for each component of each instrument. OBS waveforms exhibit good signal-to-noise ratios, though signal is typically noisier than land data due to excitation by ocean waves. OBS data also exhibit clean earthquake signals with $P$ waves well recorded on both the vertical broadband and the hydrophone channels (Figure 3 ). We obtain $>80 \%$ data recovery from 24 September 1999 (initial OBS deployment) through 25 November 1999, when many of the short-period land stations were removed.

[11] Land and OBS waveforms were compiled and arrival times analyzed within the Antelope relational database 


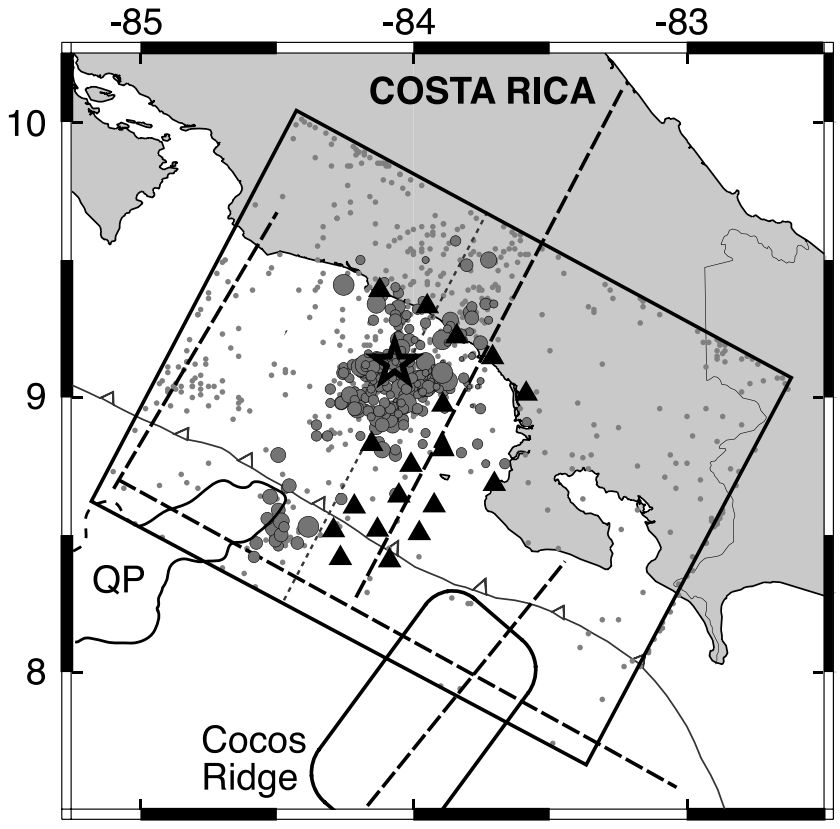

Figure 2. Overview map of the Osa experiment. The experiment primarily recorded aftershocks of the 20 August 1999 Quepos earthquake (open star). Triangles denote seismic stations. The solid box marks the boundaries of the 3 -D velocity model compiled from refraction information (heavy dashed lines) [Ye et al., 1996; Stavenhagen et al., 1998; Walther, 2003] used to relocate seismicity with QUAKE3D. High-quality, L1-norm computed QUAKE3D locations (large grey circles) are subdivided from the entire data set (grey dots) and shown scaled by local magnitude (maximum $M_{L}=3.6$ ). The light grey dashed line indicates the location of the cross section of seismicity and velocity model shown in Figure 6.

system developed by Boulder Real Time Technologies, Inc. (www.brtt.com). Initial event locations were computed within this database using the global IASP91 model, and local magnitudes were calculated using $P$ wave arrivals recorded by land stations that exhibit good signal-to-noise ratio. We recorded 15,515 arrival times for local events within or near the network boundaries, $8063 P$ wave and $7452 S$ wave arrivals. Arrival time quality was defined by error bounds set by the analyst. These numerical values can be translated into standard quality or weighting values for use by earthquake location algorithms. $S$ wave quality is generally poorer than $P$ wave quality. We pick fewer $S$ wave arrivals, and the reported mean and median reading error for the $S$ wave data set $(0.21$ and $0.13 \mathrm{~s}$, respectively) is greater than that for the $P$ wave data set $(0.18$ and $0.11 \mathrm{~s}$, respectively). Figure 1 shows initial locations for all events located using the global IASP91 velocity model with symbols scaled by local magnitude; note that most events occur in the region of the Quepos main shock, though regional Costa Rica seismicity and outer rise earthquakes were also recorded.

\subsection{Relocation Procedure and Velocity Models}

[12] We relocate events using both absolute and relative earthquake location techniques to best resolve the aftershock pattern of the 1999 Quepos earthquake. High-resolution earthquake relocation requires either accurate a priori knowledge of velocity structure or a high-quality data set to allow for joint hypocenter velocity model inversion. Velocity models are related to hypocentral parameters through the calculation of travel times, and there is a strong nonlinear trade-off between velocity and hypocenter location [e.g., Crosson, 1976; Kissling, 1988; Thurber, 1992]. Within subduction zones, $P$ and $S$ wave velocity models should be solved for separately if possible; evidence from Chile and Japan [Husen et al., 1999; Shinohara et al., 1999] suggests $V_{P} / V_{S}$ can vary considerably in subduction zones. We investigate inversion resolution and the question of variable $V_{P} / V_{S}$ by first calculating the best $P$ and $S$ wave 1 -D velocity models and hypocentral parameters using the 1-D inversion algorithm VELEST [Kissling et al., 1995]. We also construct an a priori 3-D velocity model using velocity information from reflection and refraction data (Figure 2) for use in the nonlinear, grid-searching location program QUAKE3D [Nelson and Vidale, 1990]. In order to

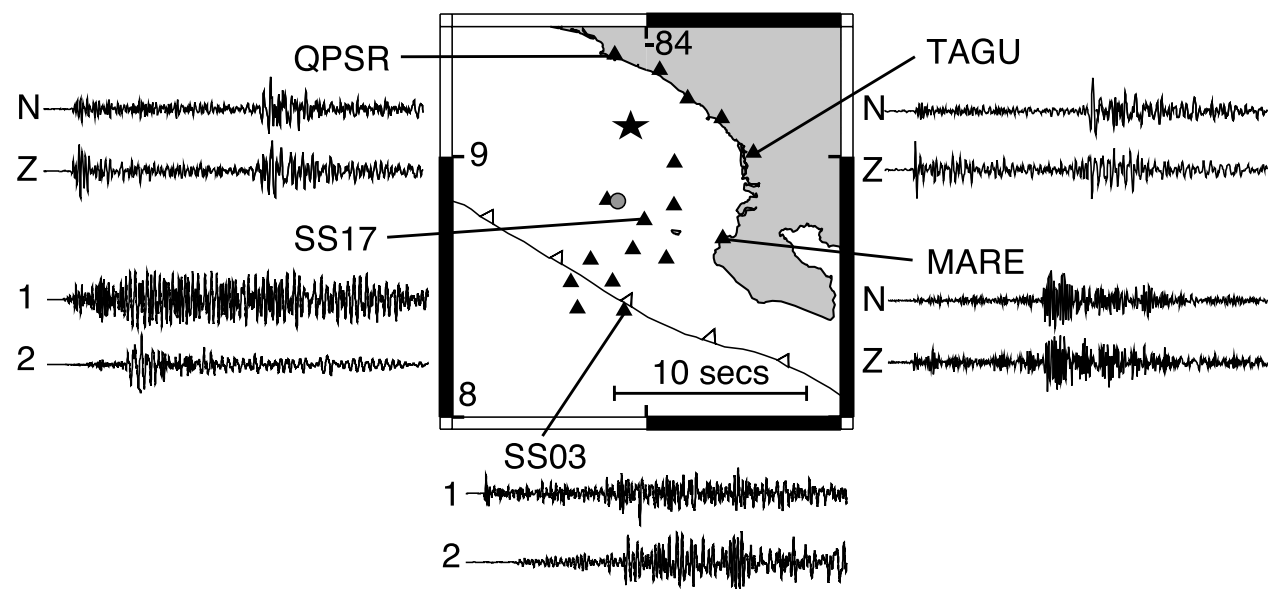

Figure 3. Example waveforms from a $M_{L} 2.4$ aftershock (grey circle) of the 1999 Quepos main shock (black star) recorded on 26 October 1999. Waveforms are band-pass filtered between 1 and $10 \mathrm{~Hz}$ and are $20 \mathrm{~s}$ in length. Note the high quality of the broadband OBS data; 1 is the vertical channel and 2 is a horizontal. MARE is the only broadband land station in the array. 

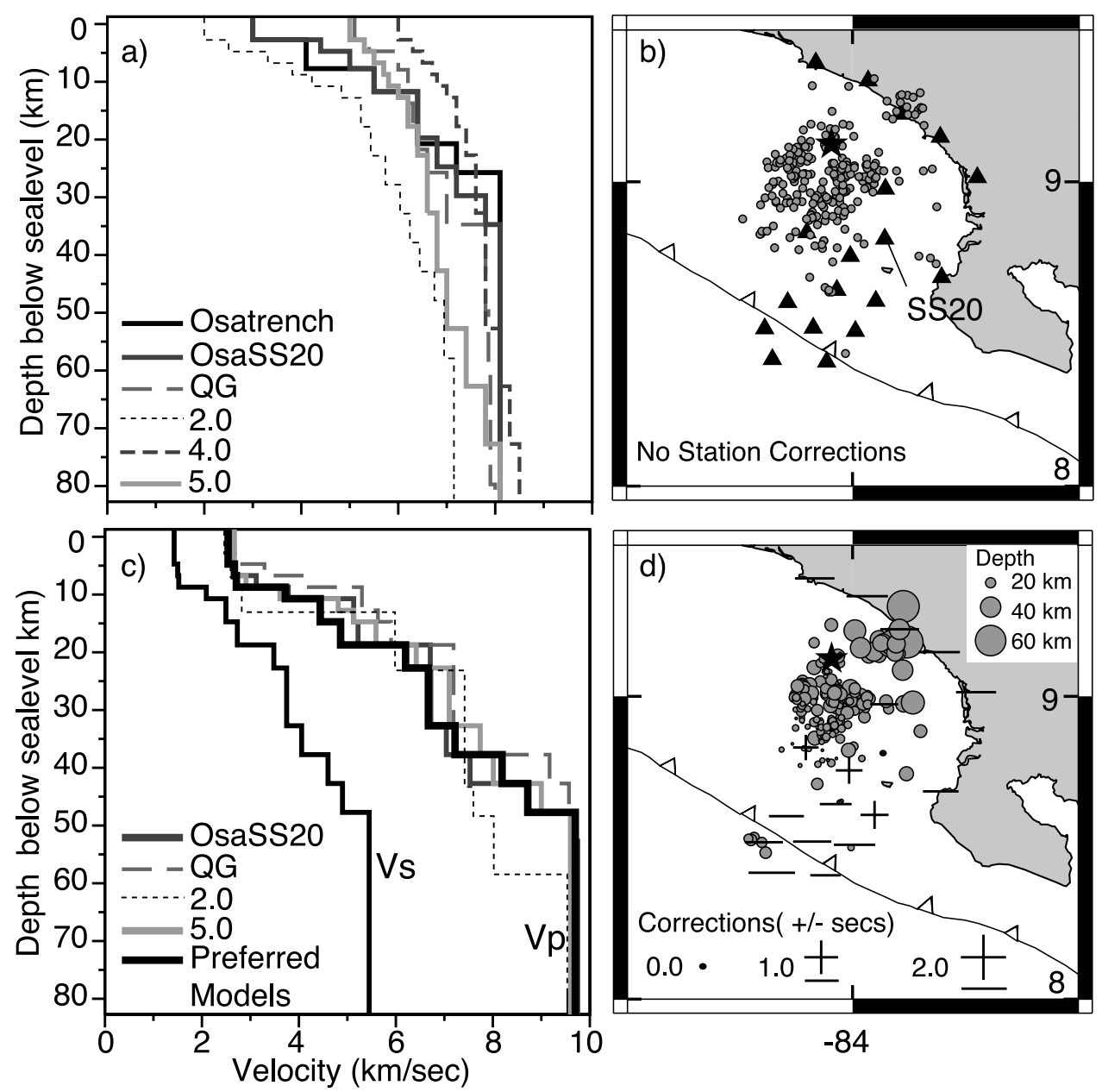

Figure 4. (a, b) Initial and (c, d) final 1-D velocity models, hypocenter locations, and the final $P$ wave station corrections (Figure 4d) calculated using VELEST. The 1-D velocity models are used to minimize root-mean-square (RMS) arrival time residuals. Initial 1-D models are OsaSS20, based on the refraction model of Stavenhagen et al. [1998] below reference station SS20; Osatrench based on the oceanic crust located seaward from the MAT of Walther [2003]; QG based on the published velocity solution of Quintero and Güendel [2000]. Models 2.0, 4.0, and 5.0 more fully sample the velocity space. The final average $P$ wave model (preferred model) is an approximation to the convergence of the more finely layered initial $P$ wave velocity models. The $V_{S}$ model is calculated using a constant $V_{P} / V_{S}$ value of 1.78. Hypocenters in $\mathrm{d}$ are scaled by depth below sea level.

test the geometry of the absolute locations along the plate interface and explore spatial clustering within the aftershock sequence, we relocate hypocenters using hypoDD, a relative relocation program that utilizes an arrival time differencing technique within a 1-D velocity model [Waldhauser and Ellsworth, 2000].

\subsubsection{One-Dimensional Velocity Model and Location Technique}

[13] We solve for the best 1-D $P$ wave velocity model and variable $V_{P} / V_{S}$ by using the routine VELEST (version 3.1) [Kissling et al., 1995]. The algorithm calculates travel times through ray tracing [Lee and Stewart, 1981] and simultaneously solves for velocity model, station corrections, and hypocenters. Use of the minimum 1-D velocity model and coupled station corrections produces the minimum event arrival time residuals for a given data set. We begin with six initial $P$ wave velocity models that span a wide range of velocity space and Moho depths (Figure 4a). We perform initial inversions using a data set composed of 165 events with $>10 P$ wave arrivals and a GAP (greatest azimuthal separation) of $<180^{\circ}$ based on initial locations within Antelope (Figure 4b). We choose the most centrally located and continuously recording station (SS20, Figure 4b) as the reference station, the station with no arrival time correction. The velocity models and station corrections from initial inversions using $P$ wave data shift hypocenters southward from the initial 1-D locations. This results in more events satisfying the GAP criteria, and we reselect 199 events (with $2370 P$ arrivals, $1953 S$ arrivals) that satisfy the previous $P$ wave criteria and additionally have $>5 S$ wave arrivals to solve for the final $P$ and $S$ wave velocity models and station corrections (Figures $4 \mathrm{c}$ and $4 \mathrm{~d}$ ). The unreasonably high velocities indicated for depths below $40 \mathrm{~km}$ (Figure 4c) reflect a severe decrease in ray coverage due to the small $(<20)$ number of events below $30 \mathrm{~km}$. There is also a strong dependence in the upper $6 \mathrm{~km}$ on the choice of reference 
station due to velocity differences between the underlying oceanic sediment and continental rock. Therefore only the depth range between $\sim 6$ and $35 \mathrm{~km}$ of the 1-D model is well resolved.

[14] The minimum $P$ wave 1-D model contains an estimate of Moho depth consistent with other published 1-D velocity models for Costa Rica [Protti et al., 1996; Quintero and Güendel, 2000], and it provides a representation of the upper 30-40 km consistent with published refraction information for the region [Stavenhagen et al., 1998]. Inversion for $V_{S}$ never resulted in a stable, consistent, and/or geologically reasonable $S$ wave velocity model. We therefore use the final $P$ wave velocity results (Figure $4 \mathrm{c}$ ) as input in hypoDD and use a constant $V_{P} / V_{S}$ of 1.78 to generate an $S$ wave model. This ratio minimizes data variance and RMS arrival time residuals and is consistent with previous studies in central Costa Rica [Protti et al., 1995b; Quintero and Güendel, 2000]. Hypocenters (Figure 4d) determined using the preferred $P$ and $S$ wave models exhibit increased clustering and a reduction in total event residual; the final hypocenter data set has a mean event residual of $0.45 \mathrm{~s}$ compared to that of the initial database locations of $0.75 \mathrm{~s}$. Hypocenters are consistently shifted toward the reference station and the final values of both $P$ wave and $S$ wave station corrections (Figure $4 \mathrm{~d}$ ) are highly variable, indicating significant 3-D heterogeneity. Because of the small number of data and the poor spatial resolution of the model based on ray coverage we do not pursue a 3-D local tomography study nor choose to interpret the resulting hypocenters from the 1-D solution.

\subsubsection{Three-Dimensional Velocity Model and Location Technique}

[15] We develop a 3-D $P$ wave velocity model utilizing 2-D refraction information and surface geology for geometric and velocity constraints. Numerous published and unpublished refraction data exist for offshore central and southern Costa Rica [Ye et al., 1996; Stavenhagen et al., 1998; Walther, 2003] (Figure 2), providing absolute velocity values, velocity gradients, and depths of sharp velocity contrasts. Stavenhagen et al. [1998] provide velocity data through the region of aftershock activity, and data from Walther [2003] provide velocities along the crest of the Cocos Ridge and perpendicular to the strike of the ridge near the MAT. Where velocity information does not exist, we interpolate velocity layers linearly along strike. We model the Osa Peninsula as a rectangular box of higher velocity material; surface geology indicates the peninsula is primarily composed of ophiolitic material [Gardner et al., 1992]. Refraction information from Ye et al. [1996] forms the north boundary of the model, allowing for accurate representation of the change in dip of the subducted plate from the Osa to the Nicoya Peninsula. The resultant 3-D velocity model is $176 \mathrm{~km} \times 226 \mathrm{~km} \times 80 \mathrm{~km}$, with a grid spacing of $1 \mathrm{~km}$. It encompasses the Osa Peninsula, the central seamount-dominated oceanic crust, and the deformed forearc from the trench to the central volcanic chain (Figure 2). We use the $V_{P} / V_{S}$ average value of 1.78 to calculate a corresponding $S$ wave velocity model.

[16] The QUAKE3D suite of programs combines a finite difference travel time calculator [Vidale, 1990; Hole and Zelt, 1995] with a grid search earthquake location algorithm [Nelson and Vidale, 1990] to locate earthquakes within an arbitrarily complex 3-D velocity volume. The program solves for $P$ and $S$ wave travel times from each station to all points in a defined grid. The finite difference approach has many advantages over traditional ray tracing: (1) it automatically follows the first arrival and ignores multipathed arrivals; (2) it follows diffractions through shadow zones; (3) it solves for any number of points within a volume; and (4) it inherently addresses curved wave fronts [Vidale, 1990]. Algorithm improvements made by Hole and Zelt [1995] increase the processing speed by solving for multiple sources simultaneously and by better accommodating sharp velocity contrasts. The earthquake location algorithm finds those grid points that minimize arrival time residuals for all station arrival pairs using either L1 or L2 norm criterion and then interpolates between these grid points to find the local minimum residual [Nelson and Vidale, 1990]. The L1 criterion minimizes the sum of the absolute values of travel time residuals while the L2 criterion minimizes the mean square travel time residual (see Nelson and Vidale [1990] for further details). Comparison of the two methods has shown that the L1 norm method is less influenced by outliers in a data set and hence is better for sparse station coverage [Nelson and Vidale, 1990]. Theoretically, minimum location error using either method should be $0.1-1 \mathrm{~km}$ based on the $1 \mathrm{~km}$ grid spacing of our velocity model. We expect higher errors, however, due to the large gap in station coverage, velocity model uncertainty, and reading errors.

\subsubsection{Relative Relocation Technique}

[17] We compute relative locations using hypoDD (version 1.0), an arrival time differencing location algorithm that solves for the relative locations of event pairs within a closely spaced cluster [Waldhauser and Ellsworth, 2000]. HypoDD uses ray tracing to calculate travel times within a layered 1-D velocity model similar to the technique used by VELEST. The double-difference technique solves for the relative location of two spatially related events recorded at common stations. For closely spaced events, ray paths from each event to each common station should be nearly identical, and differences in observed and predicted travel times should only reflect the relative difference in event location. Event-station pairs are created by linking common arrivals through a nearest neighbor approach. HypoDD iteratively minimizes arrival time residuals using weighted least squares methods, either a singular value decomposition (SVD) approach or a conjugate gradient approach (LSQR). SVD performs well for small systems (hundreds not thousands of events) and produces more accurate error estimates than the computationally efficient LSQR method [Waldhauser and Ellsworth, 2000]. We use the minimum 1-D $P$ wave velocity model discussed earlier and a constant $V_{P} / V_{S}$ of 1.78 for relative earthquake locations.

\section{Results}

[18] The Osa Experiment recorded over 1000 local, regional, and teleseismic earthquakes including aftershocks of the 1999 Quepos earthquake, Panama Block, Caribbean, and Cocos intraplate earthquakes, and activity along the outer rise. Approximately 20 local or regional events occurred per day, and frequency-magnitude calculations indicate catalog completeness to $M_{L} 1.9$ (Figure 5), an 




Figure 5. Frequency-magnitude relationship of the Osa experiment data set. Both the mean number of earthquakes normalized to a year (light grey) and the cumulative number of earthquakes in the 3 month data set (dark grey) are plotted against local magnitude. The data set is complete to $M_{L}=1.9$ with a $b$ value equal to 1.0 (dashed lines). Deviations at high magnitudes are likely due to bias toward local earthquakes or the small sample of the data set. Some regional earthquakes were included in the data set, and teleseismic events were ignored.

improvement of the OVSICORI Costa Rica network completeness to $M_{L}$ 2.5. Aftershocks and oceanic intraplate activity dominate the data set with $\sim 600$ events occurring within the boundaries of the 3-D velocity model described previously based on initial Antelope IASP91 locations (Figure 1). We focus event relocations on those events within the station network coverage recorded by both land and ocean stations with a minimum of 10 arrivals, including both $P$ and $S$ waves.

\subsection{Three-Dimensional Velocity Model and Hypocenters}

[19] Absolute earthquake relocations using QUAKE3D are ranked based on arrival quality, GAP, reported location errors, and event RMS residual. High-quality hypocenters use $>10 P$ and $S$ wave arrivals combined, exhibit a GAP $<180^{\circ}$, and have final RMS arrival time residuals within one standard deviation of the mean RMS arrival time residual for the data set. For the Osa data set, calculating earthquake locations using the L2 norm versus the L1 norm criteria produces a greater number of high-quality events, 399 versus 381 respectively. Comparison of absolute locations using the L1 and L2 norm residual computation methods show a mean epicenter difference of $2.6 \mathrm{~km}$ and depth change of $3.4 \mathrm{~km}$ (Table 1), primarily resulting from a difference in the number and distribution of phases retained in the location determination. As both methods produce similar locations using the same average number of phase arrivals, 14.95 and 14.67 arrivals per event for L2 and L1, respectively, the L1 norm locations are favored due to a significant decrease in arrival time residual for each event. Average RMS residuals calculated using the L1 norm method $(0.16 \mathrm{~s})$ are on the same order as, but slightly higher than, the median arrival time reading error for $P$ and $S$ wave data ( 0.11 and $0.13 \mathrm{~s}$, respectively), as expected for wellconstrained event locations. However, we assign the highest quality rating only to those events that are retained in both the L1 and L2 data sets (Figure 2). We include a cluster of outer rise events that occur near the outer boundary of the OBS array for interpretation purposes, although these events violate the maximum GAP criteria, and both errors and hypocenter locations are therefore poorly constrained, particularly in depth. We use the highest quality events (267) for interpretation purposes, to determine earthquake location sensitivity to changes in velocity model and arrival information, and to estimate true location errors.

[20] In order to explore the effect of velocity model on earthquake location within the Osa data set, we compute event locations with QUAKE3D using 2-D and several 3-D model variants. The initial 3-D model based on refraction information (referred to herein as OSA3D) contains a high level of structural detail that may affect event locations. Such details include a plate interface low-velocity zone, a shallowing of the oceanic plate dip to the south, and velocity gradients within both the oceanic and continental plates (see cross section in Figure 6). Most events within the Osa network locate within the model space most heavily influenced by the velocities and plate geometry (slab dip $17^{\circ}$ ) reported by Stavenhagen et al. [1998]. We test for sensitivity to the dip of the slab in the aftershock region by

Table 1. Earthquake Location Differences Due to Model and Norm Criteria

\begin{tabular}{lcccc}
\hline \multicolumn{1}{c}{ Models } & $\begin{array}{c}\text { Absolute Latitude, } \\
\text { OSA3D_ }\end{array}$ & $\begin{array}{c}\text { Absolute Longitude, } \\
\mathrm{km}\end{array}$ & $\begin{array}{c}\text { Distance, } \\
\mathrm{km}\end{array}$ & \multicolumn{2}{c}{$\begin{array}{c}\text { Absolute Depth, } \\
{ }^{\mathrm{a}}\end{array}$} \\
\hline L1, L2 & $0.9(\mathrm{n})$ & $0.9(\mathrm{n})$ & 2.6 & $3.4(+)$ \\
L1, 1Dvelest-L1 & $3.0(-)$ & $4.0(+)$ & 10.1 & $7.4(+)$ \\
L2, 1Dvelest-L2 & $2.9(-)$ & $2.9(+)$ & 8.4 & $6.5(+)$ \\
L1, OSA2D-L1 & $1.1(\mathrm{n})$ & $1.0(\mathrm{n})$ & 2.9 & $4.9(+)$ \\
L1, NoLVZ-L1 & $0.5(+)$ & $0.6(\mathrm{n})$ & 1.6 & $2.4(-)$ \\
L1, NoGrad-L1 $^{\mathrm{c}}$ & $1.5(-)$ & $1.4(-)$ & 4.1 & $4.8(+)$ \\
L1, StaCor-L1 & $0.5(-)$ & $0.5(+)$ & 1.4 & $1.7(-)$ \\
L1, Ponly L1 & $1.5(\mathrm{n})$ & $1.6(\mathrm{n})$ & 4.4 & $4.7(+)$ \\
L1, OBSonly L1 & $2.5(+)$ & $2.8(+)$ & 7.6 & $6.9(-)$ \\
\hline
\end{tabular}

${ }^{\text {a}}$ Shift of first model relative to second: $\mathrm{n}$ indicates no shift; minus indicates N,E, deeper; plus indicates S,W, shallower.

${ }^{b}$ No low-velocity zone above the plate interface.

${ }^{\mathrm{c}}$ No gradient smoothing between velocity layers.

${ }^{\mathrm{d}}$ Station corrections applied. 
a)

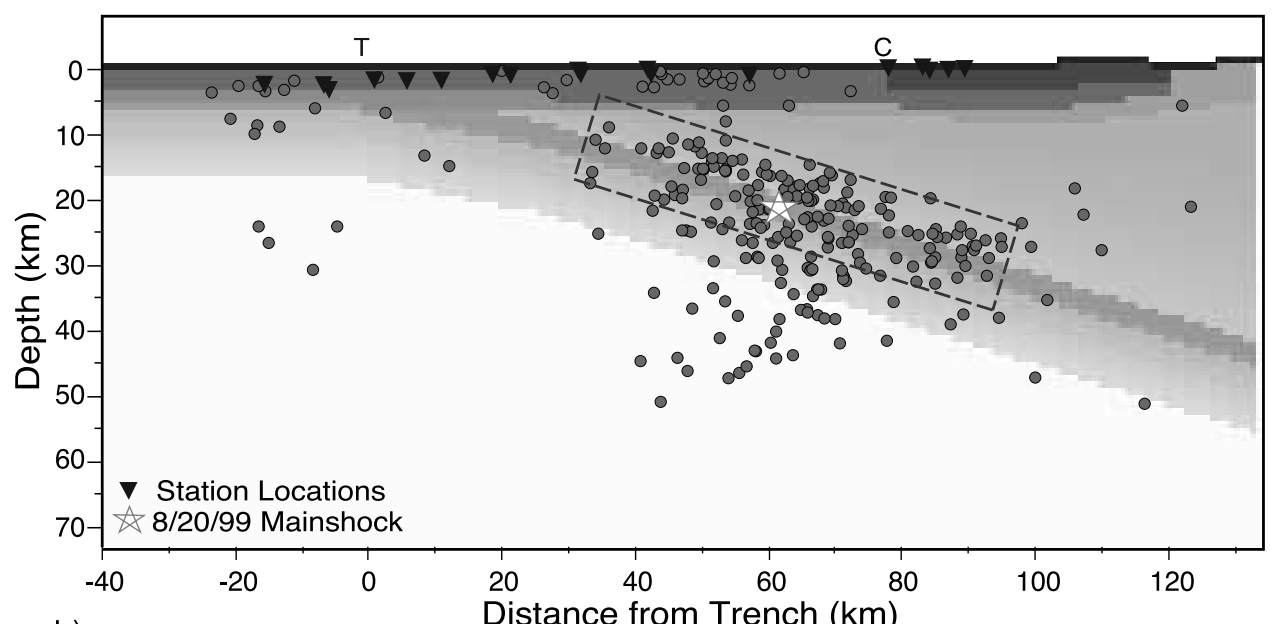

b)

Distance from Trench $(\mathrm{km})$

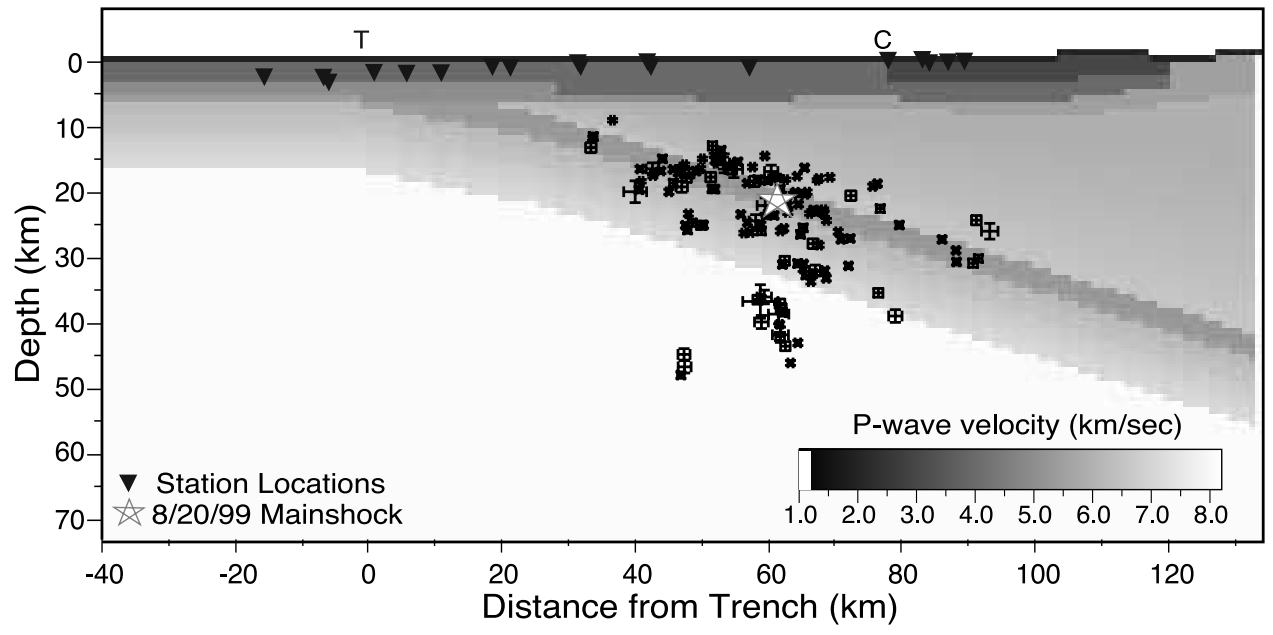

Figure 6. (a) QUAKE3D and (b) hypoDD earthquake relocations plotted on a cross section of the preferred 3-D velocity model (OSA3D), approximately corresponding to the Stavenhagen et al. [1998] refraction line. Inverted triangles indicate locations of the seismic stations; $\mathrm{T}$ and $\mathrm{C}$ mark the trench and coastline respectively. In Figure 6a, locations using QUAKE3D and the 3-D velocity model (dots) define a dipping plane corresponding to the plate interface but show significant scatter around the 20 August 1999 main shock (star). The dashed box surrounds events interpreted as interplate aftershocks. In Figure 6b, HypoDD relative locations (black error bars centered on corresponding hypocenter) using the SVD method have error estimates for interface events on the order of $1 \mathrm{~km}$. Note relative hypocenters were solved for through the preferred 1-D velocity model (shown in Figure 4c), and event clusters were adjusted in absolute space using QUAKE3D absolute locations.

increasing slab dip throughout the model using the northernmost refraction information from Ye et al. [1996]. We in effect create a 2-D model that eliminates the Osa Peninsula structure as well; the revised velocity model is hence referred to as OSA2D in Table 1. Average event distance and depth differences between locations through the 3-D and 2-D models are 2.9 and $4.9 \mathrm{~km}$, respectively (Table 1). Removing velocity gradients from the initial 3-D model, which increases velocity layer thickness and causes a decrease in resolution, or removing the low-velocity zone between the oceanic and continental plates along the thrust interface results in average location changes of $1.6-4.8 \mathrm{~km}$ (Table 1) and negligible residual changes. Application of station corrections, calculated from the average residuals for each station for $P$ and $S$ wave arrivals, results in a mean epicentral distance change of $1.4 \mathrm{~km}$ and depth change of $1.7 \mathrm{~km}$ (Table 1). Average RMS residuals calculated for the 2-D and 3-D velocity model variants range between 0.18 and $0.20 \mathrm{~s}$, greater than the OSA3D average RMS value of $0.16 \mathrm{~s}$. We conclude that event locations are not sensitive to reasonable modifications of the 3-D structure but are sensitive to the extension of a 1-D or 2-D velocity model to 3-D. The hypocenters calculated using velocity model OSA3D retain a larger number of arrivals and possess the smallest event RMS residuals; this model is therefore preferred over 2-D and 3-D model variants and used in all further testing and interpretation.

[21] Earthquake hypocenters and associated errors reflect arrival time type and quality as well as network coverage. We relocate events within the OSA3D model using only 
$P$ wave data to test location sensitivity to $S$ wave data; Gomberg et al. [1990] showed that inclusion of welldetermined $S$ wave arrival data can significantly improve earthquake depth estimates. Resulting locations have a mean epicentral distance difference of $4.4 \mathrm{~km}$ and a mean $4.7 \mathrm{~km}$ shift downward in depth (Table 1) and an average RMS residual of $0.21 \mathrm{~s}$. We test the importance of onshore versus offshore data by the removal of land station data, though this creates a large gap in network coverage. Hypocenters move an average of $7.5 \mathrm{~km}$ in epicentral distance and $6.8 \mathrm{~km}$ in depth, illustrating the importance of using both onshore and offshore network information for calculating location of offshore earthquakes. Comparisons using land stations only were not carried out due to the geometry of the land network and the small number of events recorded by $>10 P$ and $S$ wave arrivals at land stations.

[22] Final error estimates for absolute locations using the best 3-D model (OSA3D) are conservatively $3 \mathrm{~km}$ in epicentral distance and $5 \mathrm{~km}$ in depth. These conservative error estimates reflect the mean event error values reported for distance and depth within QUAKE3D and also incorporate the error estimates due to using L1 versus L2 norm criteria, varying velocity model structure and dimension, and using arrival quality information. As such, these values likely represent a maximum error estimate. Errors of $3 \mathrm{~km}$ and $5 \mathrm{~km}$ reported here apply to those events located on or near the subducting plate interface; errors for events outside the station coverage, such as outer rise activity, would be greater.

[23] The majority of events within the Osa data set form a plane dipping at $19^{\circ}$ interpreted as the seismogenic interface between the Cocos Plate and Panama Block (Figure 6a), in good agreement with dip values computed from seismic reflection, refraction, and geodetic estimates. Previous location studies using land network data were only able to resolve a cloud-like pattern of seismicity near the shallow plate interface [e.g., Protti et al., 1994, 1995a]. Scatter in the QUAKE3D data set is asymmetric with more outliers occurring within the oceanic plate rather than the upper plate, and scatter increases outside the coverage of the station network, especially downdip. Oceanic intraplate earthquakes occur directly below the seismogenic zone and appear in all QUAKE3D iterations using a variety of velocity models. A few events locate deeply enough to occur within the oceanic mantle based on comparisons with refraction information; these events are left uninterpreted due to the small number of events and potential for large depth error.

\subsection{Relative Relocation of Hypocenters}

[24] We compute relative relocations of events using hypoDD [Waldhauser and Ellsworth, 2000] to further identify plate interface events and to explore the relative error estimates for these well-resolved interplate aftershocks. Location error within hypoDD is highly dependent on station geometry, data quality, and the maximum separation between events in a pair, where maximum separation is small compared to typical event-station distances [Waldhauser and Ellsworth, 2000]. The data quality and station geometry of the Osa experiment have been discussed previously. The mean event separation within the clustered Osa data set is
$5.5 \mathrm{~km}$, well within the average station separation of $\sim 20 \mathrm{~km}$ of the Osa array, and events within the aftershock region are linked by 14 arrivals, a value similar to the 14.67 average arrivals/event used for location by QUAKE3D. Locations are calculated within the minimum 1-D velocity model using the LSQR and singular value decomposition (SVD) matrix inversion methods, and $S$ wave weighting of 0.50 relative to $P$ wave weighting. We retain the $P$ and $S$ wave qualities defined by the analyst and used within QUAKE3D as discussed earlier. The LSQR method solves for relative relocations quickly while the SVD method produces more reliable error estimates for small data sets. The number of events located within the Osa station array is very small $(<300)$, and we therefore focus discussion on the SVD results.

[25] HypoDD does not solve for absolute location of hypocenters, and therefore cluster locations need to be shifted to visualize results in absolute space. We correct cluster locations based on the uniform shift between the hypoDD relocations and corresponding QUAKE3D absolute locations. This is an arbitrary correction, and therefore hypoDD results are not interpreted for absolute location. 138 of the 267 high-quality QUAKE3D hypocenters are contained within the 224 hypoDD events, and we use these locations to correct cluster centroids. The maximum cluster shift was $2.1 \mathrm{~km}$ both horizontally and in depth with the hypoDD clusters uniformly locating slightly deeper and landward from the QUAKE3D locations. Shifting cluster location does not affect the error calculations for individual events as reported errors are relative errors based on the relocations of events within a given cluster rather than the absolute location of the events. Most aftershocks lie within $\sim 10 \mathrm{~km}$ of the interface shown in Figure $6 \mathrm{~b}$ based on scatter within the relative relocation results. Mean relative errors for these events were $0.7 \mathrm{~km}$ epicentral distance and $0.8 \mathrm{~km}$ depth. Figure $6 \mathrm{~b}$ shows the shifted hypoDD plate interface event locations with associated relative error bars plotted on a cross section through the OSA3D velocity model.

\section{Discussion}

[26] We define the up and downdip rupture limits of the 1999 Quepos earthquake using the statistical approach outlined by Pacheco et al. [1993] and applied by Husen et al. [1999] to the 1995 Antofagasta aftershock sequence. QUAKE3D hypocenters with depths within $5 \mathrm{~km}$ of the low-velocity layer defining the plate interface are interpreted as interplate earthquakes (boxed events in Figure 6a) and plotted by depth distribution using a bin size of $2.5 \mathrm{~km}$ (Figure 7). The depth distribution of this data set is best fit by a double Gaussian, consistent with reported distributions for other subduction zones [Pacheco et al., 1993; Husen et al., 1999]. The 5th percentile of the depth distribution defines the updip limit of seismicity for the Osa data set at $10 \mathrm{~km}$ depth, $30-35 \mathrm{~km}$ from the Middle America Trench, and the 95th percentile defines the downdip limit at $30 \mathrm{~km}$ depth, $\sim 95 \mathrm{~km}$ from the trench. Use of the 5 th and 95th percentiles accounts for location errors and incompleteness within the data set [Pacheco et al., 1993]. Systematic focal mechanism determinations for these events are currently underway to further constrain the nature of interplate seismicity. 


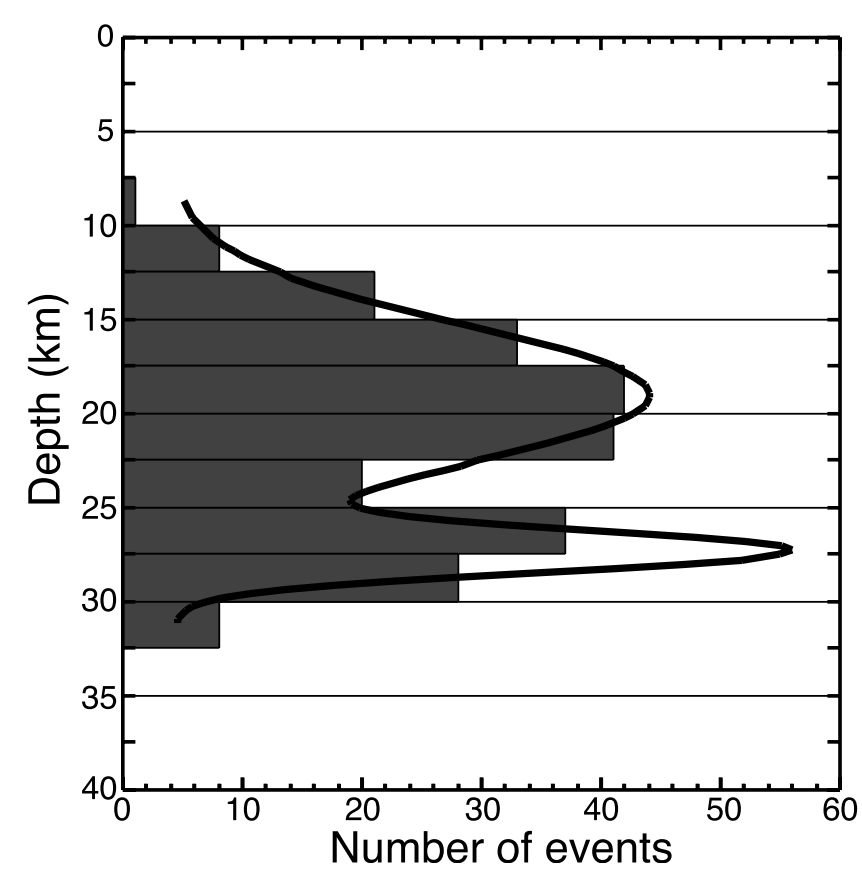

Figure 7. Depth distribution of interplate seismogenic zone earthquakes. The number of events located within $5 \mathrm{~km}$ of the Cocos/Panama Block plate interface (box in Figure 6a) are plotted versus depth using $2.5 \mathrm{~km}$ depth bins. A double Gaussian (solid line) distribution best fits the data set. The 5 th percentile occurs at $10 \mathrm{~km}$ below sea level and the 95th percentile at $30 \mathrm{~km}$, defining the statistically significant updip and downdip limit of aftershock rupture.

[27] Characteristics of the 1999 Quepos main shock rupture [Bilek et al., 2003] and its aftershock sequence appear to be strongly influenced by the morphology of the downgoing plate. Deformation of the margin and uplift of the forearc along central Costa Rica have led investigators to suggest that incoming seamounts reach seismogenic depths offshore Costa Rica [Protti et al., 1995b; von Huene et al., 1995, 2000; Husen et al., 2002]. Analysis of the spatial and temporal patterns within the aftershock sequence reveals details of the structure of the subducted plate. The along-strike extent of the aftershock pattern coincides with the width of the main shock rupture determined from waveform inversion [Bilek et al., 2003] and with the along-strike width of the Quepos Plateau (Figure 8). Temporal relationships within the aftershocks indicate a fine-scale structure to the main shock rupture asperity at depth. Most larger aftershocks occur within the first month of recording, corresponding to 30-60 days after the main shock, and almost all events downdip of the main shock and events on the outer rise occur at this time (Figure 9a). Later aftershocks, more than 60 days after the main shock, generally occur updip of the main shock and define two linear streaks that lie parallel to the incoming Quepos Plateau (Figure 9b). These parallel streaks have a spatial separation similar to bathymetric highs within the Quepos Plateau suggesting the morphology of the subducted Cocos Plate beneath the main shock mimics that of the incoming oceanic plate. Therefore aftershock relocations support the Bilek et al. [2003] interpretation that the 1999 Quepos earthquake ruptured topographic highs at depth.

[28] If bathymetric highs within the Quepos Plateau act as rupture asperities, or areas of concentrated moment release, and if asperity size limits the extent of rupture, then the 1999 Quepos earthquake may not have ruptured the updip and downdip extent of the plate interface capable of stick slip behavior. Instead, we suggest that limiting conditions controlling the transition from stick-slip to stable sliding behavior may change over the seismic cycle and that the subduction of highly disrupted seafloor in the vicinity of the 1999 Quepos earthquake has established a set of conditions which presently limit the seismogenic zone to be between 10 and $35 \mathrm{~km}$ depth below sea level. In this scenario, different segments of plate boundaries in different stages of the earthquake cycle would display spatial variations in up and downdip limits of seismicity. Such alongstrike variability in the updip limit of the seismogenic zone

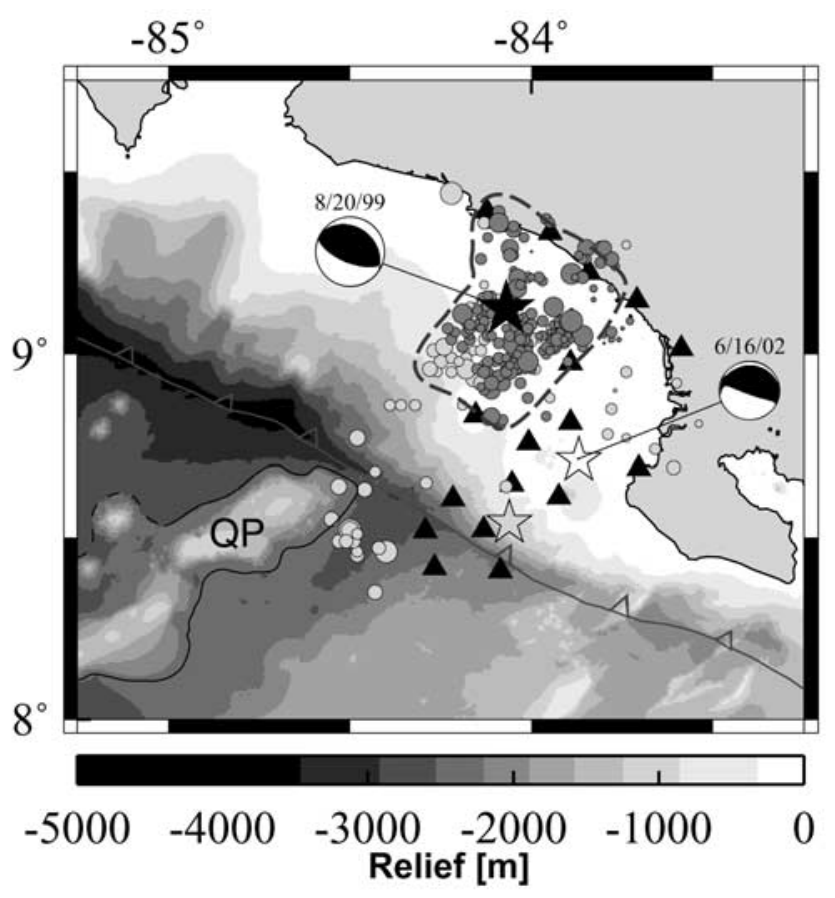

Figure 8. Best QUAKE3D earthquake locations. Earthquakes occurring along the seismogenic plate interface (dark grey circles) define the region ruptured in the 20 August 1999 earthquake (dashed line). Grey circles indicate the outer rise events, oceanic intraplate events, and continental intraplate events discussed in the text. Some events are left uninterpreted within the aftershock rupture area due to inconsistent depth locations with map view locations. The aftershock sequence occurs directly downdip of the extension of the Quepos Plateau and associated seamounts (QP as outlined) and has an aspect ratio similar to incoming seamounts. In addition to the 1999 Quepos main shock, a $M_{W} 6.4$ underthrusting earthquake occurred south of the study area in 2002 (grey star, OVSICORI location, and white star, NEIC location and focal mechanism). 

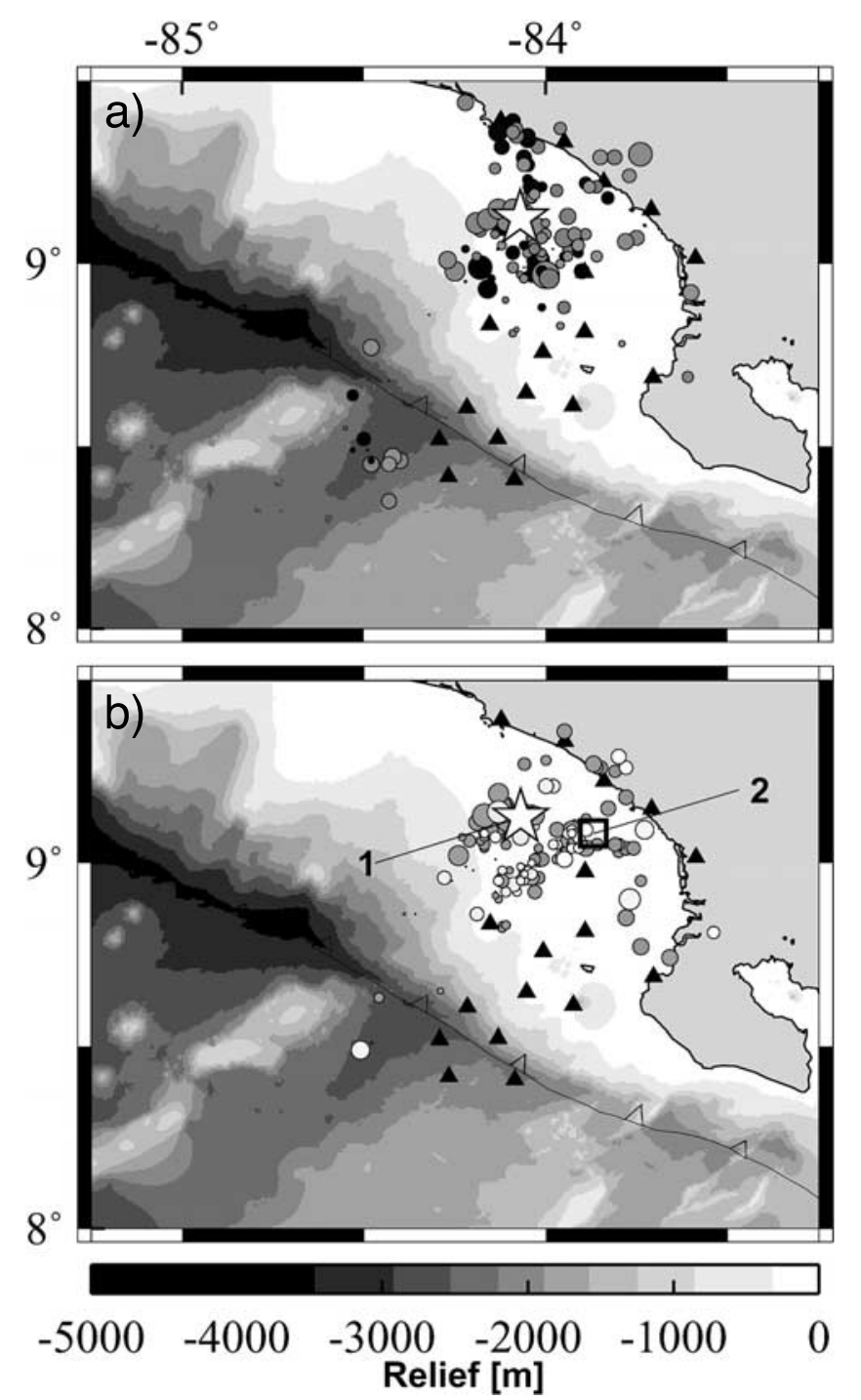

Figure 9. Temporal aftershock pattern, scaled by local magnitude. Colors reflect date of event; darker shading occurs closer to the date of the main shock (star). (a) Events recorded between 24 September 1999 and 20 October 1999 include events downdip of the main shock and a number of outer rise earthquakes. (b) Events recorded 3 months after the main shock (21 October 1999 to 20 November 1999) occur updip of the main shock and are concentrated along two linear streaks that correspond with an updip extension of two main patches of moment release defined by Bilek et al. [2003] (star and box).

offshore Costa Rica is supported by the initial shallow location and depth $(10-15 \mathrm{~km})$ of a $M_{w} 6.4$ June 2002 underthrusting earthquake that occurred to the southeast of the 1999 Quepos aftershock area (Figure 8). Variability in the updip limit of interplate seismicity was also reported in northern Costa Rica where Newman et al. [2002] found evidence of an abrupt transition in the updip limit of microseismicity under the Nicoya Peninsula. Our evolving image of the seismogenic zone is one in which updip and downdip limits vary as a function of time within an earthquake cycle, and perhaps over longer periods, and these limits reflect temporal variations in critical parameters influencing the transition from stick-slip to stable sliding behavior. Although we believe that these critical parameters change with time, exactly what these conditions are, how long they will persist, and how they may change over time is unknown. It is therefore still instructive to compare the snapshot of the seismogenic zone illuminated by the aftershocks of the 1999 Quepos earthquake with various models that seek to describe the static depth extent of seismogenic zones.

[29] Possible mechanisms controlling the transition from aseismic to seismic behavior along the updip limit of seismogenic zones include the mechanical backstop model [Byrne et al., 1988], thermally controlled mineral transition models [Vrolijk, 1990; Hyndman et al., 1997], and combinations of mechanical and thermal controls [Hyndman et al., 1997; Moore and Saffer, 2001]. Byrne et al. [1988] suggested that unconsolidated, overpressured sediments support aseismic slip along the plate interface below the accretionary wedge while stronger, more coherent rocks in the crystalline upper plate backstop support higher levels of shear stress and therefore support stick-slip earthquakes. We can disregard this model in south central Costa Rica because wedge sediments only extend to $\sim 5 \mathrm{~km}$ depth here [Stavenhagen et al., 1998] while interplate seismicity begins near $10 \mathrm{~km}$ depth. Correlations between updip limits of seismicity and thermal modeling of the 100$150^{\circ} \mathrm{C}$ isotherms have been observed in Chile, Alaska, southwest Japan, and northern Costa Rica [Oleskevich et al., 1999; Newman et al., 2002], supporting the idea of a temperature influenced updip limit. Vrolijk [1990] suggested the clay-mineral transition of smectite to illite between 100 and $150^{\circ} \mathrm{C}$ controls the transition from aseismic to seismic slip, while Moore and Saffer [2001] provided a number of examples of diagenetic to low-grade metamorphic and consolidation processes that also occur between 100 and $150^{\circ} \mathrm{C}$. Plate interface temperatures for central Costa Rica just north of the Quepos main shock have been estimated using conductive thermal models to be between 120 and $185^{\circ} \mathrm{C}$ at $10 \mathrm{~km}$ depth under variable values of shear stress $(0-50 \mathrm{MPa})$ along the plate interface (S. M. Peacock, Arizona State University, personal communication, 2002). Additionally, heat flow and temperature estimates calculated in the region of the 1999 Quepos aftershocks from the depth to the bottom-simulating reflector (BSR), a commonly noted reflection within forearcs that marks the bottom of the methane stability field, place the $100-150^{\circ} \mathrm{C}$ isotherms much shallower than $10 \mathrm{~km}$ [Pecher et al., 2001; I. Grevemeyer, University of Breman, Germany, personal communication, 2002]. Possible discrepancies between temperature estimates from BSR data and conductive thermal modeling not incorporating such data will need to be resolved in order to reliably correlate the updip extent of aftershock rupture to temperature isotherms.

[30] The lack of a well-defined continental Moho and the dearth of well-constrained thermal models for central Costa Rica leaves little downdip information with which to compare the $30 \mathrm{~km}$ depth limit of the aftershock sequence. Tichelaar and Ruff [1993] suggested that the downdip transition from seismic to aseismic behavior correlates with 
mineral property transitions from stick-slip to stable sliding and conditionally stable behavior as the subducting plate becomes ductile at higher temperatures $\left(\sim 350-450^{\circ} \mathrm{C}\right)$ and pressures. Hyndman et al. [1997] suggested an alternative process for low-temperature subduction zones in which the downgoing plate encounters the upper forearc mantle before temperatures reach $350^{\circ} \mathrm{C}$. If the mantle wedge contains serpentinite, a rock believed to exhibit both stable sliding and strain rate-dependent conditionally stable behavior under laboratory conditions, stick-slip behavior would no longer be supported along the plate interface once it is in contact with the mantle wedge. Thermal models for central Costa Rica indicate interface temperatures of $220-250^{\circ} \mathrm{C}$ at $30 \mathrm{~km}$ depth for 10-20 MPa of shear stress (S. M. Peacock, Arizona State University, personal communication, 2002). Increasing the amount of shear stress upward of $50 \mathrm{MPa}$ is required to obtain temperatures of $\sim 350^{\circ} \mathrm{C}$ at $30 \mathrm{~km}$ depth using conductive thermal models. This amount of shear heating would result in a temperature near $180^{\circ} \mathrm{C}$ at $10 \mathrm{~km}$ depth (S. M. Peacock, Arizona State University, personal communication, 2002), making the updip value more consistent with estimates made from BSR data. Although the continental Moho under central and southern Costa Rica has never conclusively been imaged, it most likely intersects the subducted plate deeper than $30 \mathrm{~km}$ [Matumoto et al., 1977; Protti et al., 1995b; Stavenhagen et al., 1998]. If the south central Costa Rican subduction zone is hotter than characterized by present thermal models, as indicated for the shallow portion of the seismogenic zone by BSR data, the downdip limit of seismicity at $30 \mathrm{~km}$ may have a strong thermal influence.

\section{Conclusions}

[31] We identify four types of earthquakes occurring offshore central Costa Rica within the station coverage of the Osa experiment: (1) aftershocks of the 20 August 1999 Quepos underthrusting earthquake, (2) outer rise earthquakes, (3) intraplate oceanic events below the interplate seismogenic zone, and (4) intraplate upper crust events. Individual depth error estimates for events located within the oceanic mantle are difficult to constrain, and these events are left uninterpreted. Intraplate oceanic events correlate spatially and temporally with the aftershock sequence of the Quepos earthquake and may be the oceanic plate response to changes in strain and fluid flow within the system. The small magnitude outer rise events reported here occur within $\sim 60$ days of the main shock and may have been triggered by the Quepos event, following a previous suggestion for outer rise activity recorded after the $M_{W} 7.0$ Nicoya Gulf event in 1990 [Protti et al., 1995b]. Upper plate activity has been previously noted in microseismicity studies of subduction zones [e.g., Shinohara et al., 1999], and the relationship of these events to general seismicity patterns in Costa Rica is an avenue of further research. Errors reported for well-constrained aftershocks along the plate interface, estimated from consideration of velocity model error, reading error, and station geometry, are $3 \mathrm{~km}$ horizontally and $5 \mathrm{~km}$ in depth. These errors are consistent with microseismicity errors reported within other subduction zones using OBS data in conjunction with nonsimulta- neous inversion location techniques [e.g., Hino et al., 1996; Shinohara et al., 1999]. Relative relocation of interplate events significantly improves the resolution of the aftershock rupture pattern however, with relative error estimates for closely spaced interplate events of $<1 \mathrm{~km}$ in distance and depth.

[32] Interplate aftershocks appear confined to a narrow zone corresponding to the interface between the Cocos Plate and Panama Block. The majority of well-located aftershocks occur below $10 \mathrm{~km}$ depth, 30-35 km from the trench and above $30 \mathrm{~km}$ depth, $95 \mathrm{~km}$ from the trench (Figure 8). The aftershock sequence correlates spatially with the downdip extension of the Quepos Plateau, and the locations of these events (Figure 8) may reflect the size and detailed structure of topographic features at depth that ruptured in the 1999 Quepos earthquake. We believe that slip during the 1999 main shock and aftershock sequence represents the present limits to stick-slip behavior along this portion of the MAT; however, we believe these limits very likely change over the earthquake cycle as physical and chemical parameters influencing the transition from stick-slip to stable sliding vary. Comparisons of recorded seismicity to available thermal and mechanical models for the updip and downdip limits of the seismogenic zone place the updip limits of seismicity at $120-185^{\circ} \mathrm{C}$ and the downdip limit between $\sim 250$ and $350^{\circ} \mathrm{C}$. Neither result is inconsistent with proposed temperature-influenced models for the transition from stick-slip to stable sliding behavior and vice versa, but further modeling is necessary to fully resolve the temperature influence on seismicity in this region.

[33] Acknowledgments. We thank Alan Sauter and Sharon Escher for the OBS fieldwork and data processing components of this project, GEOMAR and Jorge Bialas for the use of R/V Sonne cruise SO-144 Legs $1 \mathrm{a}$ and $3 \mathrm{~b}$ for OBS deployment and recovery, Frank Vernon for Antelope database management and programming training, and Floribeth Vega for OVSICORI-UNA data processing. Discussions with Andrew Newman and reviews by Cliff Thurber, Roland von Huene, and Stephan Husen improved the quality of the manuscript greatly. Some instruments used in the field program were provided by the PASSCAL facility of the Incorporated Research Institutions for Seismology (IRIS) through the PASSCAL Instrument Center at New Mexico Tech. Land data collected during this experiment are available through the IRIS Data Management Center, and OBS data are available by request through L. Dorman at SIO. The facilities of the IRIS Consortium are supported by the National Science Foundation under Cooperative Agreement EAR-0004370. This work was supported by NSF grants OCE 9910609-001 to S.Y.S and 99-10350 to L.M.D.

\section{References}

Adamek, S., F. Tajima, and D. A. Wiens, Seismic rupture associated with subduction of the Cocos Ridge, Tectonics, 6, 757-774, 1987.

Barckhausen, U., C. R. Ranero, R. von Huene, S. C. Cande, and H. A. Roeser, Revised tectonic boundaries in the Cocos Plate off Costa Rica: Implications for the segmentation of the convergent margin and for plate tectonic models, J. Geophys. Res., 106, 19,207-19,220, 2001.

Bilek, S. L., S. Y. Schwartz, and H. R. DeShon, Control of seafloor roughness on earthquake rupture behavior, Geology, 31, 455-458, 2003.

Byrne, D. E., D. M. Davis, and L. R. Sykes, Loci and maximum size of thrust earthquakes and the mechanics of the shallow region of subduction zones, Tectonics, 7, 833-857, 1988.

Christeson, G. L., K. D. McIntosh, T. H. Shipley, E. R. Flueh, and H. Goedde, Structure of the Costa Rica convergent margin, offshore Nicoya Peninsula, J. Geophys. Res., 104, 25,443-25,468, 1999.

Crosson, R. S., Crustal structure modeling of earthquake data: 1. Simultaneous least squares estimation of hypocenter and velocity parameters, J. Geophys. Res., 81, 3036-3046, 1976. 
DeMets, C., A new estimate for present-day Cocos-Caribbean plate motion: Implications for slip along the Central American volcanic arc, Geophys. Res. Lett., 28, 4043-4046, 2001

Dixon, T., GPS measurements of relative motion of the Cocos and Caribbean plates and strain accumulation across the Middle America Trench, Geophys. Res. Lett., 20, 2167-2170, 1993

Fisher, A. T., et al., Heat flow on the incoming plate offshore Nicoya, Costa Rica margin: Implications for hydrothermal circulation and the thermal state of the subducting plate, Eos Trans. $A G U, 82(47)$, Fall Meet. Suppl., Abstract T22C-0922, 2001.

Fisher, D. M., T. W. Gardner, J. S. Marshall, P. B. Sak, and M. Protti, Effect of subducting sea-floor roughness on fore-arc kinematics, Pacific coast, Costa Rica, Geology, 26, 467-470, 1998.

Gardner, T. W., D. Verdonck, N. M. Pinter, R. Slingerland, K. P. Furlong, T. F. Bullard, and S. G. Wells, Quaternary uplift astride the aseismic Cocos Ridge, Pacific coast, Costa Rica, Geol. Soc. Am. Bull., 104, 219-232, 1992

Gomberg, J. S., K. M. Shedlock, and S. W. Roecker, The effect of $S$-wave arrival times on the accuracy of the hypocenter estimation, Bull. Seismol. Soc. Am., 8, 1605-1628, 1990

Hey, R. N., Tectonic evolution of the Cocos-Nazca spreading center, Geol. Soc. Am. Bull., 88, 1404-1420, 1977.

Hino, R., T. Kanazawa, and A. Hasegawa, Interplate seismic activity near the northern Japan Trench deduced from ocean bottom and land-based seismic observations, Phys. Earth Planet. Inter. 93, 37-52, 1996.

Hinz, K., R. von Huene, and C. R. Ranero, Tectonic structure of the convergent Pacific margin offshore Costa Rica from multichannel seismic reflection data, Tectonics, 15, 54-66, 1996.

Hole, J. A., and B. C. Zelt, 3-D finite-difference reflection traveltimes, Geophys. J. Int., 121, 427-434, 1995.

Husen, S., E. Kissling, E. Flueh, and G. Asch, Accurate hypocentre determination in the seismogenic zone of the subducting Nazca Plate in northern Chile using a combined on/offshore network, Geophys. J. Int., 138, 687-701, 1999.

Husen, S., E. Kissling, and R. Quintero, Tomographic evidence for a subducted seamount beneath the Gulf of Nicoya, Costa Rica: The cause of the $1990 M_{w}=7.0$ Gulf of Nicoya earthquake, Geophys. Res. Lett., 29(8), 1238, doi:10.1029/2001GL014045, 2002.

Hyndman, R. D., M. Yamano, and D. A. Oleskevich, The seismogenic zone of subduction thrust faults, Island Arc, 6, 244-260, 1997.

Kissling, E., Geotomography with local earthquakes, Rev. Geophys., 26, 659-698, 1988

Kissling, E., U. Kradolfer, and H. Maurer, VELEST user's guide-short introduction, Inst. of Geophys. and Swiss Seismol. Serv., ETH, Zurich, 1995.

Langseth, M. G., and E. A. Silver, The Nicoya convergent margin-A region of exceptionally low heat flow, Geophys. Res. Lett., 23, $891-$ 894, 1996.

Lee, W. H. K., and S. W. Stewart, Principles and Applications of Microearthquake Networks, 293 pp., Academic, San Diego, Calif., 1981.

Lundgren, P., M. Protti, A. Donnellan, M. Heflin, E. Hernandez, and D. Jefferson, Seismic cycle and plate margin deformation in Costa Rica: GPS observations from 1994 to 1997, J. Geophys. Res., 104 28,915-28,926, 1999

Marshall, J. S., D. M. Fisher, and T. W. Gardner, Central Costa Rica deformed belt: Kinematics of diffuse faulting across the western Panama Block, Tectonics, 19, 468-492, 2000.

Matumoto, T., M. Othake, G. Latham, and J. Umaña, Crustal structure of southern Central America, Bull. Seismol. Soc. Am., 67, 121-134, 1977.

McIntosh, K., F. Akbar, C. Calderon, P. Stoffa, S. Operto, G. Christeson, Y. Nakamura, T. Shipley, E. Flueh, A. Stavenhagen, and G. Leandro, Large aperture seismic imaging at a convergent margin: Techniques and results from the Costa Rica seismogenic zone, Mar. Geophys. Res., 21, 451-474, 2000.

Meschede, M., U. Barckhausen, and H.-U. Worm, Extinct spreading on the Cocos Ridge, Terra Nova, 10, 211-216, 1998.

Moore, J. C., and D. Saffer, Updip limit of the seismogenic zone beneath the accretionary prism of southwest Japan: An effect of diagenetic to lowgrade metamorphic processes and increasing effective stress, Geology, 29, $183-186,2001$

Nelson, G. D., and J. E. Vidale, Earthquake locations by 3-D finite-difference travel times, Bull. Seismol. Soc. Am., 80, 395-410, 1990.

Newman, A. V., S. Y. Schwartz, V. Gonzalez, H. R. DeShon, J. M. Protti, and L. M. Dorman, Along-strike variability in the seismogenic zone below Nicoya Peninsula, Costa Rica, Geophys. Res. Lett., 29(20), 1977, doi:10.1029/2002GL015409, 2002.

Nishenko, S. P., Circum-Pacific seismic potential: 1989-1999, Pure Appl. Geophys., 135, 169-259, 1991.

Nishizawa, A., T. Kono, A. Hasegawa, T. Hirasawa, T. Kanazawa, and T. Iwasaki, Spatial distribution of earthquakes off Sanriku, northeastern
Japan, in 1989 determined by ocean-bottom and land-based observation, J. Phys. Earth, 38, 347-360, 1990

Oleskevich, D. A., R. D. Hyndman, and K. Wang, The updip and downdip limits to great subduction earthquakes: Thermal and structural models of Cascadia, south Alaska, SW Japan and Chile, J. Geophys. Res., 104, 14,965-14,991, 1999

Pacheco, J. F., and L. R. Sykes, Seismic moment catalog of large, shallow earthquakes, 1900-1989, Bull. Seismol. Soc. Am., 82, 1306-1349, 1992.

Pacheco, J. F., L. R. Sykes, and C. H. Scholz, Nature of seismic coupling along simple plate boundaries of the subduction type, J. Geophys. Res., 98, 14,133-14,159, 1993.

Pecher, I. A., N. Kukowski, C. R. Ranero, and R. von Huene, Gas hydrates along the Peru and Middle America Trench systems, Natural Gas Hydrates: Occurrence, Distribution, and Detection, Geophys. Monogr. Ser., vol. 124, edited by C. K. Paull and W. P. Dillon, pp. 257-271, AGU, Washington, D. C., 2001.

Protti, M., F. Güendel, and K. McNally, The geometry of the Wadati-Benioff zone under southern Central America and its tectonic significance: Results from a high-resolution local seismographic network, Phys. Earth Planet. Inter., 84, 271-287, 1994.

Protti, M., F. Güendel, and K. McNally, Correlation between the age of the subducting Cocos plate and the geometry of the Wadati-Benioff zone under Nicaragua and Costa Rica, in Geologic and Tectonic Development of the Caribbean Plate Boundary in Southern Central America, edited by P. Mann, Spec. Pap. Geol. Soc. Am., 295, 309326, 1995a

Protti, M., et al., The March 25, $1990\left(M_{w}=7.0, M_{L}=6.8\right)$, earthquake at the entrance of the Nicoya Gulf, Costa Rica: Its prior activity, foreshocks, aftershocks, and triggered seismicity, J. Geophys. Res., 100, 20,34520,358, 1995b.

Protti, M., S. Y. Schwartz, and G. Zandt, Simultaneous inversion for earthquake location and velocity structure beneath central Costa Rica, Bull. Seismol. Soc. Am., 86, 19-31, 1996.

Quintero, R., and F. Güendel, Stress field in Costa Rica, Central America, J. Seismol., 4, 297-319, 2000.

Ranero, C. R., and R. von Huene, Subduction erosion along the Middle America convergent margin, Nature, 404, 748-752, 2000.

Sallarès, V., J. J. Dañobeitia, E. R. Flueh, and G. Leandro, Seismic velocity structure across the middle American landbridge in northern Costa Rica, J. Geodyn., 27, 327-344, 1999

Sallarès, V., J. J. Dañobeitia, and E. R. Flueh, Lithospheric structure of the Costa Rican Isthmus: Effects of subduction zone magmatism on an oceanic plateau, J. Geophys. Res., 106, 621-643, 2001

Sauter, A. W., and L. M. Dorman, A locking compass for determining the orientation of ocean bottom instrumentation, Eos Trans. AGU, 76(46), Fall Meet. Suppl., F367, 1995.

Shinohara, M., T. Yoshizawa, R. Hino, Y. Aoyagi, M. Nishino, T. Sato, H. Shiobara, K. Mochizuki, and K. Suyehiro, Hypocenter distribution of plate boundary zone off Fukushima, Japan, derived from ocean bottom seismometer data, Eos Trans. $A G U$, 80(46), Fall Meet. Suppl., F724, 1999.

Shipley, T. H., K. D. McIntosh, E. A. Silver, and P. L. Stoffa, Threedimensional seismic imaging of the Costa Rica accretionary prism: Structural diversity in a small volume of the lower slope, J. Geophys. Res., 97 , 4439-4459, 1992

Stavenhagen, A. U., E. R. Flueh, C. Ranero, K. D. McIntosh, T. Shipley, G. Leandro, A. Schultze, and J. J. Dañobeitia, Seismic wide-angle investigations in Costa Rica-A crustal velocity model from the Pacific to the Caribbean, Zentralbl. Geol. Palaeontol., Teil 1, 3(6), 393-408, 1998

Tajima, F., and M. Kikuchi, Tectonic implications of the seismic ruptures associated with the 1983 and 1991 Costa Rica earthquakes, in Geologic and Tectonic Development of the Caribbean Plate Boundary in Southern Central America, edited by P. Mann, Spec. Pap. Geol. Soc. Am., 295, 327-340, 1995

Thurber, C. H., Hypocenter-velocity structure coupling in local earthquake tomography, Phys. Earth Planet. Inter., 7, 55-62, 1992.

Tichelaar, B. W., and L. J. Ruff, Depth of seismic coupling along the Chilean subduction zone, J. Geophys. Res., 98, 2017-2037, 1993.

Vidale, J. E., Finite-difference calculation of traveltimes in three dimensions, Geophysics, 55, 521-526, 1990.

von Huene, R., et al., Morphotectonics of the Pacific convergent margin of Costa Rica, in Geologic and Tectonic Development of the Caribbean Plate Boundary in Southern Central America, edited by P. Mann, Spec. Pap. Geol. Soc. Am., 295, 291-307, 1995.

von Huene, R., C. Ranero, W. Weinrebe, and K. Hinz, Quaternary convergent margin tectonics of Costa Rica: Segmentation of the Cocos Plate and Central American volcanism, Tectonics, 19, 314-334, 2000.

Vrolijk, P., On the mechanical role of smectite in subduction zones, Geology, 18, 703-707, 1990 . 
Waldhauser, F., and W. L. Ellsworth, A double-difference earthquake location algorithm: Method and application to the northern Hayward Fault, California, Bull. Seismol. Soc. Am., 90, 1353-1368, 2000.

Walther, C. H. E., The crustal structure of Cocos Ridge off Costa Rica, J. Geophys. Res., 108(B3), 2136, doi:10.1029/2001JB000888, 2003.

Ye, S., J. Bialas, E. R. Flueh, A. Stavenhagen, and R. von Huene, Crustal structure of the Middle American Trench off Costa Rica from wide-angle seismic data, Tectonics, 15, 1006-1021, 1996.

Zhang, Z., and S. Y. Schwartz, Depth distribution of moment release in underthrusting earthquakes at subduction zones, J. Geophys. Res., 97, 537-544, 1992.

S. L. Bilek, Department of Geological Sciences, University of Michigan, Ann Arbor, MI 87801, USA. (sbilek@ees.nmt.edu)
H. R. DeShon and S. Y. Schwartz, Department of Earth Sciences, University of California, 1156 High Street, Santa Cruz, Santa Cruz, CA 95064, USA. (hdeshon@es.ucsc.edu; sschwartz@es.ucsc.edu)

T. H. Dixon, Rosenstiel School of Marine and Atmospheric Science, University of Miami, 4600 Rickenbacker Causeway, Miami, FL 331491098, USA. (tdixon@rsmas.miami.edu)

L. M. Dorman, Scripps Institution of Oceanography, University of California, San Diego, 9500 Gilman Drive, La Jolla, CA 92093-0220, USA. (ldorman@ucsc.edu)

E. R. Flueh, Forschungszentrum für Marine Geowisssenschaften (GEOMAR), Christian-Albrechts-University of Kiel, Wischhof, Str 1-3, D-24148, Kiel, Germany. (eflueh@geomar.de)

V. Gonzalez and J. M. Protti, Observatorio Vulcanológico y Sismológico de Costa Rica, Universidad Nacional, Apartado 2346-3000, Heredia, 3000 Costa Rica. (jprotti@una.ac.cr) 